\title{
The Human Resource System Construction during the Enterprising Development Process of Operating Public Institutions
}

\author{
Zhang Lei ${ }^{1, a}$, Yang Dapeng ${ }^{1, b}$ \\ ${ }^{1}$ College of Public Affairs, Zijingang Campus of Zhejiang University, Hangzhou, Zhe Jiang, China \\ alei_zhang@zju.edu.cn, byangdp@zju.edu.cn
}

Keywords: Operating public institutions, Enterprising, Reform, Human resource management system

\begin{abstract}
In the new economy environment, China's original public institutions exposes many long existed drawbacks, which has seriously constrained their own sustainable development, thus the comprehensive reform of public institutions has been extremely urgent. This article chooses public institutions transforming into enterprises and entering marketing economy as the research subject, and combines the modern strategic human resource management theory to analyze the human resource system construction during the enterprising development process of operating public institutions. The enterprising process of public institutions is a huge project which concerns many aspects. And the human resource system construction is the key to the success of this transform. During the human resource construction, the public institutions should emphasize on the match of their strategy and talented employees. The institution should also embrace the internet, plan the human resource strategy, improve the incentive mechanism, and construct efficient training system and reasonable salary system. With the improvement and completion of human resource system, the reform process of public institutions will be more smooth and easier to succeed.
\end{abstract}

\section{Introduction}

The functions of public institutions are to provide service for society, culture, medicine etc. Public institution is a complementary of the government, which contributes the harmonious and effective development of the society. China's public institutions' management system was built under the planned economy system, which has fallen behind the modern market ${ }^{[1]}$.

To improve the shortcomings of public institutions, maximize the service of the government and society resource, China has released some policies guiding the enterprising reform of public institutions. The reform of public institutions has achieved some positive effects, but many institutions are still constrained by the obsolete system. The unconscionable human resource management regime, unclear function classification, and inefficient staffing efficiency are the basic situations of public institutions ${ }^{[2]}$. So enterprising public institutions must construct reasonable and scientific human resource management systems.

Under this certain time and economy background, this article focuses on the human resource system of enterprising public institutions, analyzing how to adapt the human resource system to match the marketing economy.

Different from other articles that discusses public institutions as a whole, this article focus on the detailed human resource management system of public institutions on the reform process of enterprising, which is more specific and effective. Meanwhile, this article combines the modern human resource management theory, especially the Strategic human resource management theory, 
to fully discuss the staff managing in enterprising public institutions. This article explores the construction of human resource management system behind the enterprising reform of a certain public institution, and could give reference to other public institutions, which has important theoretic and practical significance.

\section{Analysis of Research Status at Home and Abroad}

\subsection{Reform Status of Public Institutions}

With the deepening reform process of public institutions, some characteristics are exposed:

(a)The reform of management system and supply of fiscal has obvious gap between the central and local governments. The central public institutions are mostly reforming from the national level, and have stronger profiting and developing capabilities. Instead, local governments and public institutions are relatively delayed, the efforts to creation of system are insufficient.

(b)Regime reform keeps being delayed. Public institutions have been always floated outside of China's political and economical reformation. The messy management, shortsighted plan and heavy financial burden are problems along with the development of public institutions ${ }^{[3]}$.

(c)The function classification of public institutions is not clear. Currently, the subject of China's public institutions' right, responsibility and interests are overlapped and crossed due to the lag of government's function reform.

(d)The enterprise layout is unreasonable, and resource is decentralized. China's public institutions are separated and run on their own best benefits, which leads to inefficient usage of financial capital.

\subsection{The Study of Strategic Human Resource Management Theory}

The theory of human resource management has been created decades ago, after going through the labor management status of focusing on the work itself, the interpersonal relationship status of focusing on employee's autonomy, and the organization behavior status of focusing on human nature, the human resource management theory gradually tends to grow mature, and it has come to the modern scientific Strategic Human Resource Management (SHRM) status which is more systematic ${ }^{[4]}$.

Different from traditional human resource management, SHRM focus more on the match of enterprise strategy and employees, instead of human-centered. SHRM is a model which the organization plans and manages the human resource to achieve its strategic goals, SHRM emphasizes on fully playing the role of human resource management by the guiding of enterprise's strategic concept.

The core concept of SHRM is to develop the human resource to create value for the enterprise. So the enterprise shall provide an environment which promotes the value of employees ${ }^{[5]}$. Authorize reasonable rights and necessary resource to employees when endowing them certain responsibilities. Enterprises should also stimulate employee's initiatives through making scientific and effective incentive mechanism, thus motivating employees creating more value for the enterprise by maximizing their own value.

\section{Human Resource Management Problems of Enterprising Operating Public Institutions}

\subsection{Analysis of Public Institutions’ Current Human Resource Management Problem}

\subsubsection{Concept Problem}

In traditional awareness, employees in public institutions have a stable and good welfare career, so employees have lower consciousness of risk in public institutions. The negative subjective 
initiative leads to negative work atmosphere, and work efficiency. And some employees entered the public institution depend on nepotism, which causes a mismatch between personal ability and work requirements.

\subsubsection{Regime Problem}

(a)The human resource configuration lacks competitive marketing regime. Motivation and elimination mechanisms are not effectively constructed, and employees' autonomy selection is often constrained.

(b)Employees' training and potential mining mechanism still need further strengthened. The assessment for employees training is not scientific and rational, which also need systematic and creative assessment regime.

(c)Scientific and rational incentive mechanisms are not effectively constructed, and lack systematism. Incentive means are simplex and lack sensible linkage, material incentives are exaggerated while the values of spiritual incentives are neglected.

\subsection{The Change of Human Resource Management Brought by Enterprising of Public Institutions}

As shown in Figure.1, the enterprising reform of public institutions will bring many changes to human resource management, some can promote the development but some can also constrain institutions’ progress.

\subsubsection{Favorable Factors}

(a)After enterprising, the setting of job stations in public institutions become more flexible, they can decide their staffing and size of employees which reduces unnecessary waste.

(b) The recruitment process is simplified and the recruitment practices become more diverse.

(c)Performance appraisal standard, rewards and punishment measures are clearer, which reduces hierarchy and bureaucracy, and promotes employees' motivation.

\subsubsection{Adverse Factors}

(a)Some employees may lose their jobs during the enterprising process, thus the resistance from current employees in public institutions is the first obstacle in the enterprising reform.

(b)The redistribution of staff on current duty concerns their own further career, but also the development of institutions.

(c)Enterprising of public institutions is to improve the efficiency of management and create larger value ${ }^{[6]}$. Some employees in the public institutions are familiar with the operation and business, their experience can guide the institution to move on the right track stably. Losing talents during enterprising reform is a huge loss for public institutions.

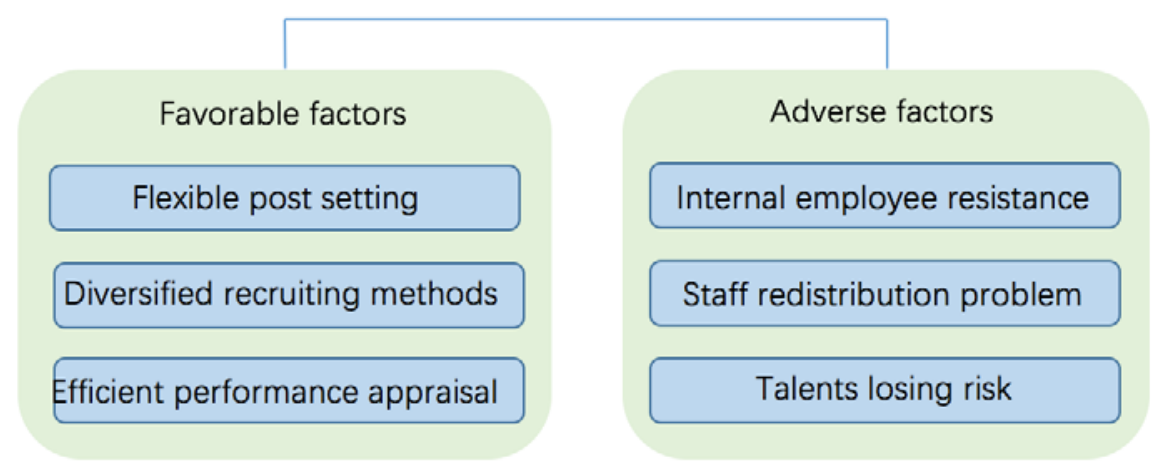

Figure. 1. Favorable and adverse factors of enterprising of public institutions. 


\section{Analysis of Human Resource Management Problems during Enterprising of Public Institutions--Taking Z Company as a Concrete Example}

\subsection{Introduction of Z Company}

Z Company is a typical public institution which focuses on media. Now Z Company has 38 traditional mainstream media subsidiaries, over 200 new emerging media subsidiaries and 0.64 billion registered memberships. But with the rise of the internet especially the mobile internet, traditional media has been challenged and affected. To adapt the new trend, $\mathrm{Z}$ Company promotes "internet-based", "user-oriented" concepts and explores "three-transformation" strategic thoughts: from the newspaper reading to diversified readings, from mass media population to focus media, and from news-centered service to integrated culture service based on news conveying.

\subsection{Problem Analysis of Z Company's Human Resource Management}

As other public institutions, Z Company has the problems on compensation and performance reviews, recruitment and promotion mechanism, training and development system, and human resource supporting systems.

(a)Compensation and performance reviews

Z Company's current salary and compensation system is simplex and lacks sensible linkage. Under the pressure of traditional business's decline and new business's slow rising, the current compensation system has inadequate attraction for excellent and integrated new media talents.

(b)Recruitment and promotion mechanism

$\mathrm{Z}$ Company cannot handle the staff adjustment and elimination regime well with the current human resource system, the rigid function system and administration levels will limit the flexibility of Z Company's internet service business. And fixed working environment will lower staff's passion for creation.

(c)Training and development system

$\mathrm{Z}$ Company's staff adjustment is relatively infrequent, and the age structure tends to be middle-aged. Staff's expertise and professional skills are more suitable for traditional media business. But Z Company's internal training and assessment mechanism haven't been established, leading to few effective trainings.

(d)human resource supporting systems

Z Company’s human resource management lacks intersectional linkage between different models, and some existing policies are not perfectly executed due to the lack of effective supporting systems such as qualification systems.

\section{Suggestions of Human Resource Management System Construction during Enterprising of Public Institutions --Taking Z company as a Concrete Example}

To ensure the successful transformation, guarantee the organization operation and system adaptation., Z Company should innovate a new human resource management system to match talents with their strategy. Figure.2 presents some suggestions for human resource management during public institutions' enterprising reform.

\subsection{Make an Inventory of the Entire Personnel}

Led by a listed company's human resource department, Z Company should summarize their previous experience on human resource management and their strengths and weakness of current human resource. By improving the systematic assessment hierarchy, Z Company should promote excellent and potential employees, and eliminates some underperforming employees. 


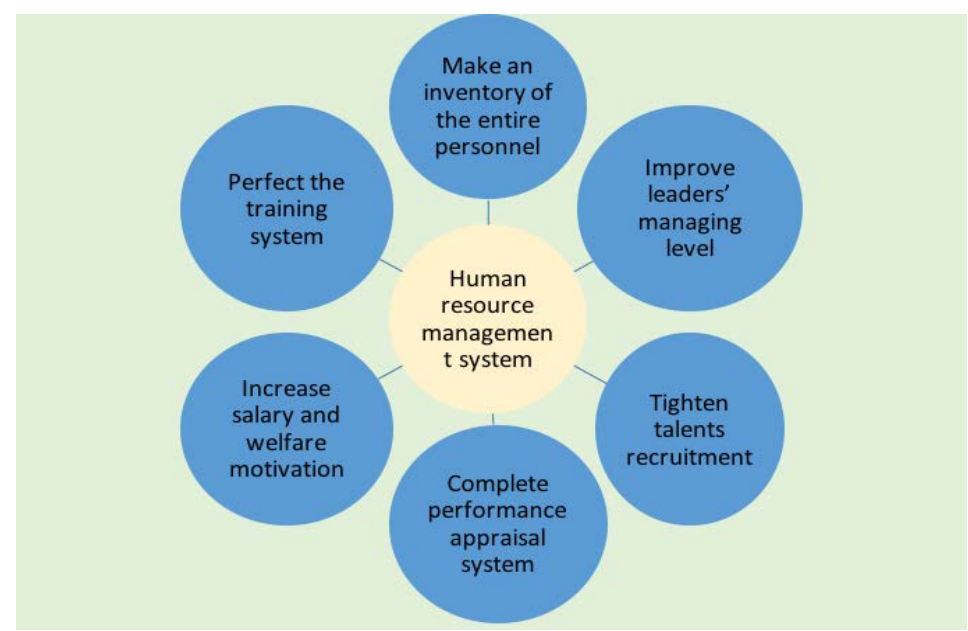

Figure. 2. Suggestions of human resource management construction during enterprising of public institutions--taking $\mathrm{Z}$ company as a concrete example.

\subsection{Improve the Managing Level of Leaders}

For companies having many subsidiaries, normative human resource system ensures a smooth running of the whole corporation, and main leaders shall be fully responsible for the management of these systems ${ }^{[7]}$. It is necessary to introduce adaptive post evaluation method and construct flexible post management system to achieve adjustable staff managing and improve the vigour of $\mathrm{Z}$ Company. Based on original post settings, classify the managing property or technical property of each post station, and determine the match of Z Company's talents with specified technical or managing post stations.

\subsection{Tighten the Talent Recruitment}

Integrate the recruitment system and regulate the recruitment process. Expand channels of talent recruitment, and carry out collectivize recruitment, Z Company should also build an intra-sharing recruitment platform to collect and release staff requirements, which can increase the effectiveness and normative of recruitment.

\subsection{Complete Performance Appraisal System}

Z Company should put forward the performance strategy, and refine the appraisal indicators. On the base of traditional performance appraisal experience, strengthen the performance feedback, design and arrange the content and methods of feedback. Internet of Things provide a platform for companies to interact with all employees and can be integrated for higher performance appraisal system ${ }^{[8]}$. Emphasizing on important and measurable performance indicators, find the essential indicators that affect the realization of final strategies by decomposing Z Company's strategy target.

\subsection{Increase Salary and Welfare Motivation}

Improve the flexibility and diversity of compensation design ${ }^{[9]}$. On the guiding of Z Company's "internet-based" strategy, build and optimize competitive and strategic compensation system to effectively attract, retain and motivate talents that $\mathrm{Z}$ Company need for transformation and upgrading.

\subsection{Accelerate the Perfection of the Training System}

Integrate internal and external training resource and innovate training methods, set up scientific training courses and optimize the training team to realize systematic, standardized, practiced and branding training management, Z Company should construct a training system which links with 
different modules of human resource. Z Company also need to strengthen the construction of their internal training team, increase the target for training team's construction and make detailed training feedback to know whether courses are well designed and executed.

\section{Conclusion and Further Discussion}

\subsection{Main Conclusions}

(a)The enterprising reformation of public institutions is the irresistible trend of marketing economy development, which also represents our country's determination of work for the people. The government plays the leading role in the enterprising reformation, and it should always keep the "all for the people" principle. The last thing that the government does is to be arbitrary, guidance and suggestion are necessary, but the institutions also need space and time

(b)The enterprising of public institutions is a huge project, which concerns the institutions' property structure, human management and other aspects. This reformation not only changes the administration frame of institutions, but also changes the fundamental human resource management system. And the scientific and effective human resource management system is the key to the success of the enterprising reformation.

(c)After the enterprising reformation, institutions will attract many talents which have different values and culture tradition. During the process of human resource system construction, institutions should consider diversified talent cultivation regime, and help them get into the new public institutions. Institutions should try to promote the development of their affairs through improving and optimizing their human resource management system.

(d)Due to the presence and development of internet, not only has the style of people's daily life been changed, but also the development directions of institutions and companies are updating. The human resource management theory has also developed into new models and theory directions. The population of internet and internet of things makes effective and scientific human resource management system possible. Public institutions should also embrace the new trend, explore their own suitable systems and improve their shortcomings with the help of instant messaging.

(e)The construction of human resource management system should pay attention to the match of institutions' strategy and talents. To achieve their long-run strategies, institutions shall make systematic and designed deployment and management on human resource management. During the enterprising, listen the opinions of current employees, and select talents which fits the long-term plan of the institution.

\subsection{Further discussion}

The enterprising reformation of public institutions is the trend of national marketing economy's development. Scientific and effective human resource management system will provide sustainable innovation and vitality, and helps the long-term growth of public institutions. This article could provide some advice for the human resource management system of enterprising public institutions. And more theory and practical experience will be explored and demonstrated.

\section{References}

[1] Xiong Wei. A Discussion on Characteristics, Problems and Countermeasures of Human Resource Management in Institutions [J]. People 's Forum. 2012(32): 58-59.

[2] Jiang K, Lepak D P, Han K, et al. Clarifying the construct of human resource systems: Relating human resource management to employee performance [J]. Human Resource Management Review, 2012, 22(2):73-85.

[3] Hou Wenjia. An Analysis of the Current Situation of Human Resource Management in China 's 
Institutions[J]. Human Resource Management. 2011(6): 68-69.

[4] Mcmahan G C. Theoretical Perspectives for Strategic Human Resource Management[J]. Journal of Management, 1992, 18(2):295-320.

[5] Becker B E, Huselid M A. Strategic Human Resource Management: where do we go from here? [J]. Journal of Management: Official Journal of the Southern Management Association, 2006, 32(6):898-925.

[6] Gittell J H, Seidner R, Wimbush J. A Relational Model of How High-Performance Work Systems Work [J]. Organization Science, 2009, 21(2):490-506.

[7] Furusawa M, Brewster C, Takashina T. Normative and systems integration in human resource management in Japanese multinational companies[J]. Multinational Business Review, 2016, 24(2):82-105.

[8] Dr A N V. Connecting the Dots: Internet of Things and Human Resource Management[J]. Social Science Electronic Publishing, 2017.

[9] Ronald J. Burke. Human resource management applications in the developing world: Empowering employees[J]. Iranian Journal of Management Studies (IJMS),2016,9(4):795-800. 